\title{
Diastolic dysfunction and markers of collagen turnover
}

\author{
Jaroslav Meluzín', Josef Tomandl² \\ ${ }^{1} 7^{\text {st }}$ Department of Internal Medicine/Cardioangiology, St. Anne's University Hospital, Masaryk University, Brno, \\ 2 Department of Biochemistry, Faculty of Medicine, Masaryk University, Brno, Czech Republic
}

\begin{abstract}
Meluzín J, Tomandl J. Diastolic dysfunction and markers of collagen turnover. Cor Vasa 2010;52:494-499.
\end{abstract}
The purpose of this paper is to summarize the current knowledge of the relationship of markers of collagen turnover to left ventricular (LV) diastolic dysfunction. There exists a strong relationship between the predominance of collagen synthesis over its degradation, myocardial fibrosis, and LV diastolic function. Some serum markers of collagen turnover were found to be practical surrogates of collagen content within the myocardium and indicators of the severity of LV diastolic dysfunction. However, the selection of optimal individual biomarkers for determination of various pathological clinical situations associated with disturbances in collagen turnover still requires further research. Key words: Diastolic dysfunction - Collagen - Biomarkers

Meluzín J, Tomandl J. Diastolická dysfunkce a markery odrážející metabolismus kolagenu. Cor Vasa 2010;52:494-499.

Cílem tohoto souhrnného článku bylo rozebrat současné znalosti o vztahu markerů metabolismu kolagenu a diastolické dysfunkce levé komory. Byl nalezen těsný vztah mezi převahou syntézy kolagenu nad jeho odbouráváním, fibrózou myokardu a diastolickou funkcí levé komory. Bylo zjištěno, že některé markery obratu kolagenu stanovené v séru odrážejí množství kolagenu v myokardu a jsou indikátory závažnosti diastolické dysfunkce levé komory. Nicméně volba optimálních biomarkerů pro určení různých patologických klinických situací, které jsou spojeny s poruchami syntézy anebo odbourávání kolagenu, ještě vyžaduje další výzkum.

Klíčová slova: Diastolická dysfunkce - Kolagen - Biomarkery

Address: prof. Jaroslav Meluzín, MD, FESC, $1^{\text {st }}$ Department of Internal Medicine/Cardioangiology, St. Anne's Hospital, Pekařská 53, 65691 Brno, Czech Republic, e-mail: jaroslav.meluzin@fnusa.cz

\section{Introduction}

Hypertension, diabetes mellitus, and ageing are the major risk factors for diastolic heart failure (= heart failure with preserved left ventricular ejection fraction, HFPEF). All these risk factors are associated with structural myocardial changes, mainly with an increase in myocardial fibrosis. Excessive accumulation of fibrotic tissue in the myocardium is the main factor accounting for the development of diastolic dysfunction and its progression to HFPEF. However, the non-invasive diagnostics of HFPEF is difficult and requires the detailed echocardiographic assessment including Doppler tissue imaging in combination with natriuretic peptide analysis. ${ }^{1}$ The purpose of this paper is to summarize the current knowledge of the relationship of diastolic dysfunction to structural myocardial disturbances, and to discuss whether markers of collagen turnover can be used to improve the diagnostics of HFPEF.

\section{Normal myocardial structure}

The normal myocardium is composed of a variety of cells and extracellular matrix. The main cell types are cardiac myocytes, endothelial and vascular smooth muscle cells, and fibroblasts. The cardiac extracellular matrix (ECM) is composed of various types of collagen and other matrix proteins, proteoglycans, glycosaminoglycans, basement membrane proteins, and bioactive signalling molecules. ${ }^{2,3}$ The ECM has several functions. ${ }^{3}$ It serves as a storage depot for growth factors, hormones, and cytokines. The ECM provides the environment for cells to migrate, grow, and differentiate. Forming the extracellular scaffolding, it supports and aligns myocytes, thereby influencing both the myocardial contraction and relaxation. In addition, a structural supporting network maintains myocardial geometry during the cardiac cycle. ${ }^{2}$ ECM disturbances are involved in the initiation, progression, and maintenance

The study was supported by a grant of the Ministry of Education of the Czech Republic (MSM, No. 0021622402). 
of adverse left ventricular (LV) remodelling. Type I being dominant and type III collagens are the major fibrillar collagens. They create the collagen network that can be subdivided into three components: epimysium, perimysium, and endomysium. ${ }^{4}$ A perimysial weave surrounds and groups muscle fibres into bundles, while an endomysial weave surrounds individual myocytes. Perimysial strands connect adjacent muscle bundles to one another. Epi-, peri-, and endomysial components of the collagen network ensure support and alignment of myocytes preserving myocardial thickness and architecture, prevent from muscle fibre and cardiac myocyte slippage, and assist in relengthening of myocytes. The fibrillar collagen network is also important for transduction of myocyte-generated force to the ventricular chamber. Finally, it forms the basis for myocardial stiffness and protects the myocytes from overstretch.

\section{Myocardial structure under the pathological conditions}

The structural homogeneity of healthy myocardial tissue is governed by equilibrium between the stimulator and inhibitor signals of cell growth. These signals regulate cell growth, apoptosis, and collagen turnover. An excess of stimulators, due to either their absolute overproduction or the deficit of inhibitors, promotes fibrosis. Myocardial fibrosis is a disproportionate accumulation of fibrillar collagen in the myocardium. Fibrosis of the heart is mainly caused by chronic elevations in hormones of the renin-angiotensin-aldosterone system (RAAS). ${ }^{5}$ The main impulse for RAAS activation is renal ischemia. On the other hand, cardiac tissue homogeneity is preserved when myocyte growth, induced by ventricular pressure or volume overload, is not accompanied by circulating RAAS activation. ${ }^{5}$ Thus, myocyte hypertrophy appears to be a response to increased load placed on the ventricular chamber, while fibroblast growth and collagen turnover are altered in response to hormonal agents. A disproportionate involvement of non-cardiomyocyte cells, as seen in advanced hypertensive heart disease (i.e. tissue heterogeneity), causes pathological remodelling of tissue structure. Typically, fibroblasts contribute to perivascular fibrosis, which extends to contiguous interstitial space. ${ }^{5}$ The extensive structural remodelling of the ECM, typically found in patients with hypertension, results in an increase in heart weight and elevation of the collagen volume fraction (a morphometric measure of the amount of collagen). Querejeta et $\mathrm{al}^{6}$ found in patients with essential hypertension a collagen volume fraction ranging from $2.08 \%$ to $9.83 \%$ compared with $1.39 \%$ to $2.15 \%$ in normal hearts. In hearts with mild hypertrophy, a diffuse reactive accumulation of interstitial fibrosis without scarring is mostly found. In hearts with moderate and severe hypertrophy, the severity of diffuse interstitial fibrosis increases and microscopic foci of scarring can be observed. Myocardial fibrosis impairs the relengthening of myocytes during the myocardial relaxation thereby leading to relaxation abnormalities. In addition, accumulation of fibrous tissue increases myocardial stiffness that appears to be the major factor resulting in diastolic dysfunction and diastolic heart failure. Brilla et $\mathrm{al}^{7}$ demonstrated the association of the degree of myocardial fibrosis with the severity of LV diastolic dysfunction. In contrast, ventricular hypertrophy without structural changes in hypertrophied ventricles in athletes does not alter tissue stiffness.

\section{Markers of collagen turnover}

ECM is controlled by cardiac fibroblasts through several mechanisms: ${ }^{3}$ a) through the synthesis and deposition of matrix molecules, b) through matrix degradation and turnover by the production and release of matrix metalloproteinases (MMPs) and other substances, and c) by maintaining mechanical tension of the collagen network. Under physiological conditions, the synthesis and degradation of the ECM are in equilibrium. However, under pathological situations (LV remodelling etc) an increase in the synthesis and/or a decrease in the degradation of ECM result in fibrosis characterized by an accumulation of connective tissue, primarily of collagen. Formations of perivascular and interstitial fibrosis are associated with an increase in circulating levels of angiotensin II, aldosterone, and deoxycorticosterone. ${ }^{4}$ In experimental models, both angiotensin II and aldosterone were found to increase collagen synthesis (relative to protein synthesis) in a concentration-dependent manner. A profibrotic effect was also demonstrated for homocysteine, which increases MMPs, induces myocardial collagen expression and depositions, causes coronary arterial remodelling, and instigates LV hypertrophy and diastolic dysfunction. ${ }^{8-10}$

Important agents associated with collagen turnover are various forms of collagen precursors and products of collagen degradation. Collagen types I and III are synthesized by fibroblasts as procollagens containing a small amino-terminal and a larger carboxy-terminal propeptide. After procollagens have been secreted into the ECM, the propeptides are removed by specific proteinases and released into the blood. Since they are released concurrently with collagen type I and III synthesis, some of them are clinically utilized as markers of collagen type I and III synthesis. The most clinically important ${ }^{11-17}$ are the aminoterminal propeptide of procollagen type I (PINP, marker of collagen I synthesis), the carboxy-terminal propeptide of procollagen type I (PICP, marker of collagen I synthesis, sometimes abbreviated as CICP or PIP), and the aminoterminal propeptide of procollagen type III (PIIINP, marker of collagen III synthesis, in some papers abbreviated as PIIIP). When comparing their ability to reflect collagen synthesis, PICP has the advantage of maintaining $1: 1$ ratio between the number of collagen I molecules produced and the number of PICP molecules released..$^{18}$ In contrast, the PINP and PIIINP are not completely cleaved during the conversion of procollagen types I and III into corresponding collagens. They remain in the final collagen type I and III fibres, where they can also be released during collagen fibre 
degradation..$^{18}$ A specific marker of collagen degradation is the carboxy-terminal telopeptide of collagen type I (CITP, a breakdown product of type I collagen, also abbreviated as ICTP). The amount of CITP in the circulation is proportional to the amount of fibrillar collagen degraded..$^{18}$ However, when assessing the serum levels of biomarkers, it is necessary to take into account that they are not produced only in the myocardium but also in other tissues (lung, liver, muscle, bone). In addition, as both PICP and PINP are cleared from the blood by liver endothelial cells and CITP via glomerular filtration, liver function and renal function have to be taken into account when interpreting the serum levels of biomarkers. ${ }^{19}$

Very important proteolytic enzymes are MMPs, which are responsible for ECM degradation and remodelling. There are more than 20 types of MMPs. The most important classes of MMPs are collagenases (e.g. MMP-1, MMP-8, and MMP-13), gelatinases (e.g. MMP-2, MMP-9), stromelysins and stromelysin-like MMPs, and the membrane-type MMPs. ${ }^{20}$ MMPs are regulated by a) gene transcription, b) extracellular activation of the inactive proenzyme forms by proteases, such as plasmin, cathepsin G, trypsin, or kallikrein, and c) the action of specific tissue inhibitors of metalloproteinases (TIMPs). ${ }^{21}$ Of the various TIMPs (TIMP-1, TIMP-2, TIMP-3, TIMP-4), TIMP-1 is more frequently utilized in clinical practice. ${ }^{22-24}$

\section{Hypertension and markers of collagen turnover}

Hypertension is a disease which is accompanied by the development of extensive interstitial and perivascular fibrosis, by an increase in the collagen volume fraction, and by a more intensive deposition of collagen type I. ${ }^{6,16,25}$ Querejeta et $\mathrm{al}^{6}$ performed right septal endomyocardial biopsies in 26 patients with essential hypertension to quantify collagen content. Compared with normotensives, both serum PICP and collagen volume fraction were increased in hypertensives. A direct correlation was found between the collagen volume fraction and serum PICP in all hypertensives. A cutoff of $127 \mu \mathrm{g} / \mathrm{L}$ for PICP provided $78 \%$ specificity and $75 \%$ sensitivity for the prediction of severe fibrosis. The same authors confirmed these results in a larger population of 65 hypertensives with LV hypertrophy. ${ }^{26}$ In addition, this study demonstrated that the collagen volume fraction, the extent of collagen type I deposition, and the PICP serum levels were significantly higher in hypertensives with heart failure than in hypertensives without any evidence of heart failure. In another project studying 34 patients with hypertensive heart disease, the same group of researchers ${ }^{25}$ described a significant positive correlation between the collagen volume fraction and LV chamber stiffness corroborating a strong association between the severity of myocardial fibrosis and LV diastolic properties. Progression of the severity of myocardial fibrosis was reflected by the elevation of serum levels of PICP. ${ }^{25}$ A significant correlation between serum PICP levels and myocardial fibrosis (collagen volume fraction) was also confirmed in animal experiments studying hypertensive rats. ${ }^{16}$ In this study, the treatment with quinapril reversed LV hypertrophy, markedly decreased myocardial fibrosis, and decreased the serum concentration of PICP. Thus, the serological assessment of collagen turnover markers has the potential to address myocardial fibrosis. ${ }^{16,27}$

Hypertension, LV hypertrophy, and myocardial fibrosis represent very important factors for the development of diastolic dysfunction and diastolic heart failure. Structural changes in hypertension affect primarily the subendocardium. The subendocardium contains mainly longitudinally oriented myofibres which are responsible for the longitudinal LV contraction and relaxation, and oblique myofibres forming a right-handed helix contributing to the clockwise basal and counterclockwise apical rotation creating LV torsion. ${ }^{28}$ In hypertensive patients with a normal LV ejection fraction, the earliest disturbances in LV function include the impairment of LV longitudinal deformation ${ }^{29,30}$ and an increase in LV torsion, ${ }^{29}$ while circumferential and radial deformation is preserved. ${ }^{29}$ In such patients, Kang et $\mathrm{a}^{29}$ found an elevation of the serum levels of TIMP-1, but no changes in the serum levels of PINP and PIIINP. Both impaired longitudinal strain and increased LV torsion significantly correlated with the logarithm of the serum TIMP-1 level. ${ }^{29}$ These findings suggest a change in the fibrotic process and collagen turnover in early stages of LV dysfunction involving primarily the subendocardium (increase in LV torsion in the presence of subendocardial dysfunction is caused by the predominance of subepicardial myofibres forming the left-handed helix). Worsening of LV longitudinal function in hypertensives with a normal LV ejection fraction was also described by Poulsen et al, ${ }^{30}$ but an elevation in the PIIINP plasma level was found in this study. Early changes in collagen turnover in patients with hypertension or with a combination of hypertension and diabetes occurring before the clinical manifestation of heart failure were also confirmed by other authors. ${ }^{15,17}$ However, data on the most important biomarkers reflecting increase in collagen turnover are conflicting. Alla et al ${ }^{15}$ and Laviades et $\mathrm{al}^{17}$ demonstrated the importance of the elevation in serum levels of PIIINP. Li-Saw-Hee et $\mathrm{al}^{31}$ described a decrease of MMP-9 and TIMP-1 serum levels in 32 patients with untreated hypertension. Opposite results (elevation of MMP-9 and TIMP-1) were found by Tayebjee et $\mathrm{a}^{22}$ in 74 patients with essential hypertension. Timms et $\mathrm{a}^{23}$ found elevation of TIMP-l but not PIIINP plasma levels in hypertensive patients. Franz et $\mathrm{al}^{32}$ described a significant elevation of serum levels of MMP-9 but not of TIMP-1, -2, -4 in patients with arterial hypertension and LV concentric or eccentric hypertrophy. Patients with concentric hypertrophy (septum and posterior wall $>13 \mathrm{~mm}$, no LV dilation) had significantly higher MMP-9 levels than patients with eccentric hypertrophy (LV enddiastolic diameter $>55 \mathrm{~mm}$ and LV end-systolic diameter $>40 \mathrm{~mm}$ ). Thus, MMP-9 might be useful as a serum marker of LV hypertrophy in hypertensive patients. Another marker 
which was found to relate with concentric LV hypertrophy was PIIINP. ${ }^{33}$ Díez et al $^{27}$ described an increase in serum concentrations of PIIINP and PICP in patients with essential hypertension. Serum PICP directly correlated with the LV mass index, while PIIINP was inversely related to the ratio between early and late transmitral flow velocity. These findings suggest that tissue synthesis of collagen type I and III is abnormally increased in patients with essential hypertension and reinforce the fact that hypertension is a condition characterized by fibrogenic hyperactivity. The same authors described elevation of serum levels of PICP but not CITP in spontaneously hypertensive rats ${ }^{16}$ and in patients with hypertensive heart disease, ${ }^{25}$ suggesting that the intensity of the extracellular degradation of collagen type I is not enough to equilibrate the increased extracellular synthesis of collagen type I.

Concerning MMPs, Walter et $\mathrm{al}^{34}$ demonstrated in animal experiments that the development of LV hypertrophy induced by supracoronary banding is associated with increased gene expression for MMP-1, MMP-2, MMP-3, MMP-9, TIMP-1, and TIMP-2, and decreased gene expression of TIMP-3, indicating an increased collagen turnover. After regression of LV hypertrophy following the surgical correction of aortic stenosis, there was a complete regression of gene expression to baseline values. Thus, an up-regulation of MMP gene expression is associated with pathological LV hypertrophy. The change in ECM gene expression can be considered a part of the LV adaptive process. Heymans et $\mathrm{al}^{35}$ took cardiac biopsies in 36 patients with aortic stenosis and in 29 control patients without LV hypertrophy. Collagen deposition was greater in aortic stenosis patients than in controls and was most pronounced in aortic stenosis patients with severe diastolic dysfunction (pseudonormal or restrictive LV filling pattern). Cardiac expression of TIMP-1 and TIMP-2 (but not of MMP-1, MMP-2, and MMP-9) was significantly increased in patients with aortic stenosis and was related to the degree of interstitial fibrosis and diastolic dysfunction. ${ }^{35}$

In summary, there exists a strong association between the predominance of collagen synthesis over its degradation, exaggerated collagen accumulation in the myocardium, and increased LV chamber stiffness in patients with hypertension. Several biomarkers have been found to reflect increased LV hypertrophy (MMP-9, PIIINP, PICP) and myocardial fibrosis (PICP) in hypertensives. However, due to relatively small cohorts of patients studied and, sometimes, conflicting results, future larger and carefully designed projects are necessary to confirm the ability of collagen turnover markers to predict the severity of myocardial fibrosis.

\section{Relationship of collagen turnover to diastolic heart failure}

Diastolic heart failure (HFPEF) is characterized by myocardial collagen accumulation, mostly accompanied by LV hypertrophy, accounting for worsening of LV relaxation and elevation of myocardial and LV stiffness. Diastolic heart failure is not associated with LV dilatation and a decrease in LV ejection fraction. To date, relationships of several markers of collagen turnover to diastolic dysfunction or diastolic heart failure have been studied. Martos et al ${ }^{12}$ studied 85 hypertensive patients. Twenty of them did not have diastolic dysfunction (DD), 33 had DD without any evidence of HFPEF, and 32 patients had HFPEF. MMP-2, PIIINP, PICP, CITP, and brain natriuretic peptide (BNP) were significant predictors of DD. However, receiver operating curve analysis demonstrated that none of these variables had an area under the curve (AUC) $\geq 0.75$. When patients with HFPEF were analysed, MMP-2, MMP-9, PIIINP, PICP, CITP, and BNP were significant predictors of HFPEF. The AUC for MMP-2 was 0.91 and the cutoff value of $1585 \mathrm{ng} / \mathrm{mL}$ provided $91 \%$ sensitivity and $76 \%$ specificity for predicting HFPEF. Interestingly, the combination of MMP- 2 and BNP reached a sensitivity of $81 \%$ and a specificity of $83 \%$. Multivariate analysis identified three independent predictors of HFPEF: MMP-2, MMP-9, and PIIINP. The same study group ${ }^{13}$ also related individual biomarkers to the severity of diastolic dysfunction. There was a significant correlation between the left atrial volume index and PICP, PINP, CITP, and MMP-2. With the progression of diastolic dysfunction from impaired relaxation, over pseudonormal LV filling to restrictive LV filling, there was a significant progressive serum elevation of PICP, CITP, PIIINP, and MMP-2. These data suggest increased collagen synthesis (PICP, PIIINP) and degradation (CITP, MMP-2) (i.e. increased collagen turnover) in advanced and more severe stages of diastolic dysfunction. They also indicate a direct relationship between diastolic dysfunction and collagen excess. Recently, Mak et al ${ }^{14}$ evaluated 44 patients with HFPEF. Twenty-four of them were randomly assigned to 12-month treatment with eplerenone (an aldosterone receptor antagonist), 20 patients served as controls. PIIINP, PINP, MMP-2, interleukin-6 and interleukin-8, and tumour necrosis factor-alpha increased with time in the control group. Eplerenone treatment attenuated the increase in PIIINP at 12 months and improved LV diastolic function. This study demonstrated the progressive increase in markers of collagen turnover and inflammation in patients with HFPEF and the beneficial effect of eplerenone. Inverse correlation between serum PIIINP and maximal early transmitral velocity, suggesting the association of PIIINP with LV diastolic function, has been described by Laviades et al. ${ }^{17}$

Progression of both systolic and diastolic heart failure was associated with enhanced gene expression of type I and III collagens and TIMP-1 and TIMP-2. ${ }^{36}$ The expression and activity of MMP-2 were equally enhanced in both phenotypes; however, those of MMP-9 were more promoted in systolic heart failure, ${ }^{36}$ suggesting the role of MMP-9 in LV dilatation. A very important finding of the Nishikawa's study ${ }^{36}$ was the association of MMP-2 activation with progressive myocardial fibrosis independently of LV 
dilatation. In addition, this study demonstrated that collagen accumulation progressed even though MMP activity was enhanced. Because gene expression of collagen synthesis was also enhanced, collagen production may have overcome activation of MMPs and induced imbalance between ECM production and degradation. A detailed analysis of MMPs and their tissue inhibitors (TIMP) was provided by Ahmed et $\mathrm{al}^{37}$ in four groups of patients: 1) hypertensive patients with no LV hypertrophy (HTN group), 2) hypertensive patients with LV hypertrophy but no congestive heart failure (HTN + LVH group), 3) hypertensive patients with LV hypertrophy and congestive heart failure (HTN + $\mathrm{LVH}+\mathrm{CHF}$ group), 4) controls without any cardiovascular disease (CTL group). When comparing MMP-2, MMP-9, MMP-13, TIMP-1 and TIMP-2, there were no differences between CTL and HNT patients. Compared with controls, MMP-2 and MMP-13 were decreased while MMP-9 and TIMP-1 were increased in HNT + LVH group (suggesting decreased ECM degradation). There were no significant differences in MMP-2, MMP-9, MMP-13, TIMP-2, or MMP/TIMP ratios between $\mathrm{HTN}+\mathrm{LVH}$ and HTN $+\mathrm{LVH}+\mathrm{CHF}$ groups, but TIMP-1 was significantly increased in the group with heart failure (cutoff TIMP-1 for prediction of heart failure was $>1200 \mathrm{ng} / \mathrm{mL}$ ). There was a significant relation between TIMP-1 and the extent of diastolic dysfunction. Thus, in hypertensive patients, the elevation of TIMP-1 was predictive of LV hypertrophy and diastolic heart failure and indicated the severity of diastolic dysfunction. The importance of TIMP-1 assessment was confirmed in a study of 100 never-treated hypertensive patients and 50 normal controls. ${ }^{24}$ In this study, plasma levels of PICP, CITP, and TIMP-1 were elevated in the hypertensive cohort as a whole. PICP and CITP were not related to diastolic function assessed by echocardiography. In contrast, TIMP-1 levels correlated with indices of LV diastolic filling (E/A ratio, deceleration time of $\mathrm{E}$ wave). A TIMP-1 level $>500 \mathrm{ng} / \mathrm{mL}$ showed a specificity of $97 \%$ and a positive predictive value in predicting LV diastolic dysfunction of $96 \%$. There were no significant differences in TIMP-1 levels in groups with and without LV hypertrophy. Similarly, TIMP-1 levels did not differ between controls and hypertensive patients with normal LV diastolic filling. These findings suggest that TIMP-1 is a marker of fibrosis and LV diastolic dysfunction and is independent of both blood pressure and LV mass. In a cohort of 74 hypertensive patients, Tayebjee et $\mathrm{al}^{22}$ demonstrated that TIMP-1 but not MMP-9 levels slightly correlated with LV mass, LV mass index, and E/Ea ratio reflecting LV filling pressure. However, in a smaller cohort of untreated hypertensive patients, the relationship of TIMP-1 and LV diastolic filling (E/A) was not found. ${ }^{31}$

In summary, there is an association between biochemical markers of fibrosis and LV diastolic function. Progression of diastolic dysfunction is accompanied by the elevation of several markers of collagen turnover (PICP, CITP, PIIINP, MMP-2, TIMP-1). TIMP-1 is a potential non-invasive marker of fibrosis and LV diastolic heart failure.

\section{Application of collagen turnover markers in clinical practice}

The results of the above discussed papers suggest that some markers of collagen turnover in blood circulation have the ability to reflect structural myocardial changes, the severity of myocardial fibrosis, and the presence and progression of LV diastolic dysfunction. However, few data are available on the clinical utilization of markers of collagen turnover in large clinical trials. ${ }^{11,16,17,38-41}$ Thus, at present, we cannot recommend the determination of markers of collagen turnover for decision making in an everyday clinical practice.

However, there can be several areas for the potential clinical application of biomarkers of collagen turnover in the future. They can be used to non-invasively detect the collagen content within the myocardium and the severity of LV diastolic dysfunction. They may be utilized to control the effect of heart failure therapy or the therapy suppressing collagen synthesis. MMPs or some markers of collagen turnover may serve as therapeutic targets for the prevention of LV remodelling or pathological accumulation of fibrosis in the myocardium. Finally, some biomarkers of collagen turnover have the potential to predict the risk for cardiac events, i.e. the assessment of biomarkers may improve the risk stratification of patients with many cardiovascular diseases.

\section{Conclusion}

There exists a strong relationship between the predominance of collagen synthesis over its degradation, myocardial fibrosis, and LV diastolic function. Some serum markers of collagen turnover were found to be practical surrogates of collagen content within the myocardium and indicators of the severity of LV diastolic dysfunction. However, the selection of optimal individual biomarkers for determination of various pathological clinical situations associated with disturbances in collagen turnover still requires further research.

\section{References}

1. Paulus WJ, Tschope C, Sanderson JE, et al. How to diagnose diastolic heart failure: a consensus statement on the diagnosis of heart failure with normal left ventricular ejection fraction by the Heart Failure and Echocardiography Associations of the European Society of Cardiology. Eur Heart J 2007;28:2539-2550.

2. Spinale FG. Matrix metalloproteinases. Regulation and dysregulation in the failing heart. Circ Res 2002;90:520-530.

3. Lindsey ML, Mann DL, Entman ML, Spinale FG. Extracellular matrix remodeling following myocardial injury. Ann Med 2003;35:316-326.

4. Weber KT, Sun Y, Tyagi SC, Cleutjens JPM. Collagen network of the myocardium: function, structural remodeling and regulatory mechanisms. J Mol Cell Cardiol 1994;26:279-292.

5. Weber KT. Fibrosis and hypertensive disease. Curr Opin Cardiol 2000;15: 264-272.

6. Querejeta R, Varo N, López B, et al. Serum carboxy-terminal propeptide of procollagen type $\mathrm{I}$ is a marker of myocardial fibrosis in hypertensive heart disease. Circulation 2000;101:1729-1735. 
7. Brilla CG, Funck RC, Rupp H. Lisinopril-mediated regression of myocardial fibrosis in patients with hypertensive heart disease. Circulation 2000;102:1388-1393.

8. Miller A, Mujumdar V, Palmer $L$, et al. Reversal of endocardial endothelial dysfunction by folic acid in homocysteinemic hypertensive rats. Am J Hypertens 2002;15:157-163.

9. Joseph J, Washington A, Joseph $L$, et al. Hyperhomocysteinemia leads to adverse cardiac remodeling in hypertensive rats. Am J Physiol Heart Circ Physiol 2002;283:H2567-H2574.

10. Mujumdar VS, Aru GM, Tyagi SC. Induction of oxidative stress by homocysteine impairs endothelial function. J Cell Biochem 2001;82:491500.

11. Iraqi W, Rossignol $P$, Angioi M, et al. Extracellular cardiac matrix biomarkers in patients with acute myocardial infarction complicated by left ventricular dysfunction and heart failure. Circulation 2009;119:2471-2479.

12. Martos R, Baugh J, Ledwidge $M$, et al. Diagnosis of heart failure with preserved ejection fraction: improved accuracy with the use of markers of collagen turnover. Eur J Heart Fail 2009;11:191-197.

13. Martos R, Baugh J, Ledwidge $M$, et al. Diastolic heart failure. Evidence of increased myocardial collagen turnover linked to diastolic dysfunction. Circulation 2007;115:888-895.

14. Mak GJ, Ledwidge MT, Watson ChJ, et al. Natural history of markers of collagen turnover in patients with early diastolic dysfunction and impact of eplerenone. J Am Coll Cardiol 2009;54:1674-1682.

15. Alla F, Kearney-Schwartz A, Radauceanu A, et al. Early changes in serum markers of extra-cellular matrix turnover in patients with uncomplicated hypertension and type II diabetes. Eur J Heart Fail 2006;8:147-153.

16. Díez J, Panizo A, Gil MJ, et al. Serum markers of collagen type I metabolism in spontaneously hypertensive rats. Relation to myocardial fibrosis. Circulation 1996;93:1026-1032.

17. Laviades C, Mayor G, Díez J. Treatment with lisinopril normalizes serum concentrations of procollagen type III amino-terminal peptide in patients with essential hypertension. Am J Hypertens 1994;7:52-58.

18. López B, González A, Querejeta R, Díez J. The use of collagen-derived serum peptides for the clinical assessment of hypertensive heart disease. J Hypertens 2005;23:1445-1451.

19. López B, Gonzáles A, Varo N, et al. Biochemical assessment of myocardial fibrosis in hypertensive heart disease. Hypertension 2001;38:1222-1226.

20. Wilson EM, Gunasinghe HR, Coker ML, et al. Plasma matrix metalloproteinase and inhibitor profiles in patients with heart failure. J Cardiac Fail 2002;8:390-398.

21. Brew K, Dinakarpandian D, Nagase H. Tissue inhibitors of metalloproteinases: evolution, structure and function. Bioch Bioph Acta 2000;1477:267-283.

22. Tayebjee MH, Nadar SK, MacFadyen RJ, Lip GYH. Tissue inhibitor of metalloproteinase- 1 and matrix metalloproteinase- 9 levels in patients with hypertension. Am J Hypertens 2004;17:770-774.

23. McLean Timms $P$, Wright A, Maxwell $P$, et al. Plasma tissue inhibitor of metalloproteinase-1 levels are elevated in essential hypertension and related to left ventricular hypertrophy. Am J Hypertens 2002;15:269-272.

24. Lindsay MM, Maxwell P, Dunn FG. TIMP-1. A marker of left ventricular diastolic dysfunction and fibrosis in hypertension. Hypertension 2002;40:136-141.

25. Díez J, Querejeta R, López B, et al. Losartan-dependent regression of myocardial fibrosis is associated with reduction of left ventricular chamber stiffness in hypertensive patients. Circulation 2002;105:2512-2517.

26. Querejeta R, López B, González A, et al. Increased collagen type I synthesis in patients with heart failure of hypertensive origin. Relation to myocardial fibrosis. Circulation 2004;110:1263-1268.
27. Díez J, Laviades C, Mayor G, et al. Increased serum concentrations of procollagen peptides in essential hypertension. Relation to cardiac alterations. Circulation 1995;91:1450-1456.

28. Buckberg G, Hoffman Jl, Mahajan A, et al. Cardiac mechanics revisited. The relationship of cardiac architecture to ventricular function. Circulation 2008;118:2571-2587.

29. Kang SJ, Lim HS, Choi BJ, et al. Longitudinal strain and torsion assessed by two-dimensional speckle tracking correlate with the serum level of tissue inhibitor of matrix metalloproteinase-1, a marker of myocardial fibrosis, in patients with hypertension. J Am Soc Echocardiogr 2008;21:907-911.

30. Poulsen SH, Andersen NH, Heickendorff L, Mogensen CE. Relation between plasma amino-terminal propeptide of procollagen type III and left ventricular longitudinal strain in essential hypertension. Heart 2005;91:624-629.

31. Li-Saw-Hee FL, Edmunds E, Blann AD, et al. Matrix metalloproteinase-9 and tissue inhibitor metalloproteinase-1 levels in essential hypertension. Relationship to left ventricular mass and anti-hypertensive therapy. Int J Cardiol 2000;75:43-47.

32. Franz $M$, Berndt $A$, Altendorf-Hofmann $A$, et al. Serum levels of large tenascin- $C$ variants, matrix metalloproteinase- 9 , and tissue inhibitors of matrix metalloproteinases in concentric versus eccentric left ventricular hypertrophy. Eur J Heart Fail 2009;11:1057-1062.

33. Nakahara T, Takata $Y$, Hirayama $Y$, et al. Left ventricular hypertrophy and geometry in untreated essential hypertension is associated with blood levels of aldosterone and procollagen type III amino-terminal peptide. Circ J 2007;71:716-721.

34. Walther T, Schubert A, FalkV, et al. Regression of left ventricular hypertrophy after surgical therapy for aortic stenosis is associated with changes in extracellular matrix gene expression. Circulation 2001;104(suppl I):I-54-I-58.

35. Heymans $S$, Schroen B, Vermeersch $P$, et al. Increased cardiac expression of tissue inhibitor of metalloproteinase- 1 and tissue inhibitor of metalloproteinase-2 is related to cardiac fibrosis and dysfunction in the chronic pressure-overloaded human heart. Circulation 2005;112: 1136-1144.

36. Nishikawa N, Yamamoto K, Sakata Y, et al. Differential activation of matrix metalloproteinases in heart failure with and without ventricular dilatation. Cardiovasc Res 2003;57:766-774.

37. Ahmed SH, Clark LL, Pennington WR, et al. Matrix metalloproteinases/ tissue inhibitors of metalloproteinases. Relationship between changes in proteolytic determinants of matrix composition and structural, functional, and clinical manifestations of hypertensive heart disease. Circulation 2006;113:2089-2096.

38. Sundström J, Evans JC, Benjamin EJ, et al. Relations of plasma matrix metalloproteinase- 9 to clinical cardiovascular risk factors and echocardiographic left ventricular measures. The Framingham Heart Study. Circulation 2004;109:2850-2856.

39. Vorovich EE, Chuai S, Li M, et al. Comparison of matrix metalloproteinase 9 and brain natriuretic peptide as clinical biomarkers in chronic heart failure. Am Heart J 2008;155:992-997.

40. Dhingra R, Pencina MJ, Schrader $P$, et al. Relations of matrix remodeling biomarkers to blood pressure progression and incidence of hypertension in the community. Circulation 2009;119:1101-1107.

41. Wang TJ, Larson MG, Benjamin EJ, et al. Clinical and echocardiographic correlates of plasma procollagen type III amino-terminal peptide levels in the community. Am Heart J 2007;154:291-297.

Received 24. 6. 2010 